\title{
A REVOLTA ESTUDANTIL E A LUTA PELA DEMOCRATIZAÇÃO DO SISTEMA EDUCACIONAL CHILENO
}

\author{
THE STUDENT UPRISING AND THE STRUGGLE FOR THE \\ DEMOCRATIZACION OF CHILEAN EDUCATIONAL SYSTEM
}

DOI: http//dx.doi.org/10.15448/2178-3748.2016.2.21321

\author{
Rafael Betencourt \\ Doutorando - UERJ \\ rafabetenko@gmail.com
}

\begin{abstract}
RESUMO: Desde 2011 a acção do movimento estudantil chileno vem constantemente atraindo a atenção do mundo e se apresenta actualmente como um importante ator político naquele país. A luta dos estudantes chilenos por uma educação pública e gratuita cresceu reverberando os ecos da Primavera Árabe e dos "indignados" na Europa, evidenciando uma crise do modelo de democracia representativa e indicando novamente as ruas como um forte espaço de política. Qualquer análise sociopolítica de tal movimento é dependente da compreensão do seu papel histórico naquela sociedade. O presente artigo pretende abordar a formação social do movimento dos estudantes chilenos, apresentando a luta contra a herança institucional educacional estabelecida na transição da ditadura de Pinochet para o projeto consensual de uma nova democracia chilena. Dessa forma as demandas políticas dos estudantes chilenos esbarram nos limites de qualquer tipo de transformação radical imposta por um histórico consenso democrático entre direita e esquerda. As ruas ainda seguem sendo alternativa para a crise institucional de representatividade que a sociedade chilena enfrenta desde de sua transição para a democracia.
\end{abstract}

PALAVRAS-CHAVE: Movimento Estudantil, Chile, América Latina.

\begin{abstract}
Since 2011 the action of the Chilean student movement has consistently attracted the world's attention and it currently stands as an important political actor in the country. The struggle of Chilean students for a free and public education grew reverberating echoes of the Arab Spring and the "indignados" in Europe, revealing a crisis of the representative democracy model and indicating the streets once more as a strong political space. Any socio-political analysis of such moviment becames dependent on the understanding of its historical place in that society. This article aims to discuss the social formation of the current claim of Chilean students, presenting the struggle against the educational institutional legacy set along the transition of the Pinochet dictatorship to consensual design of a new Chilean democracy. Thus the political demands of Chilean students meet the limits of any kind of radical transformation imposed by a historical democratic consensus between right and left. The streets still remains as an alternative to the institutional crisis that Chilean society has faced since its transition to democracy.
\end{abstract}

KEYWORDS: Students Moviment, Chile, Latin America.

\section{Introdução}

No dia 30 de junho de 2011, a capital do Chile Santiago viu cerca de cento e vinte mil pessoas ocuparem a "La Alameda", a sua principal avenida, reivindicando uma educação pública gratuita e de qualidade. O que seria chamado de o "inverno chileno" aparecia como parte de um processo maior, como reverberação das mobilizações populares no mundo árabe 
por democracia e do movimento dos indignados na Europa que colocava em questão o modelo de integração europeia. Nesse contexto, as mobilizações estudantis no Chile poderiam apareciam em um primeiro momento como parte de um processo global de indignação, de crise de representatividade de um modelo de democracia liberal. A semelhança entre tais experiências em uma primeira análise evidencia um elo discursivo inegável, no entanto, a tentativa de construção de uma narrativa de explicação única pode ocultar aspectos cruciais para se compreender a formação histórica do movimento e das demandas estudantis daquele país.

Os estudantes chilenos ganharam rapidamente posição de destaque no cenário político do país, a maneira pela qual conseguiram ganhar crescente notoriedade e obter a adesão de outros sectores sociais se estabelecendo como importante movimento social no século XXI, resgata aspectos recentes da história do país, como o processo de transição democrática a partir da derrota de Augusto Pinochet no final da década de 1980 e o posterior projeto de consolidação dessa democracia. A negociação pacífica de retorno para a democracia e a recuperação de uma estabilidade económica ocultaram problemas estruturais que ainda limitam o aprofundamento democrático chileno. A coligação centro-esquerda que se formou para guiar a transição do regime militar para a democracia no final da década de 1980, chamada de Concertación, apresentava as fragilidades de uma negociação estabelecida para se evitar as transformações da esquerda mais radical e o retorno dos militares ao poder.

O discurso dos estudantes pontuava sua força reivindicativa na crítica contra o sistema educacional herdado do governo de Pinochet; a ausência de uma ruptura institucional mais expressiva evidenciou problemas estruturais na expansão democrática no sector da educação. Os revoltosos ocuparam escolas e universidades, realizaram diversas manifestações de rua e organizaram os rumos e as decisões do movimento através de plenárias e assembleias. $\mathrm{O}$ discurso a favor de uma educação pública gratuita é associado directamente à incapacidade do modelo neoliberal de democratizar o sistema educacional. Junto a esta demanda central da gratuidade aparece o apelo a uma nova constituição, que legitime sobretudo uma transformação do sistema político como um todo. O problema da educação é diagnosticado como resultado da continuidade institucional que a transição democrática não foi capaz de superar. A resposta do governo de Sebastian Piñera (Presidente do Chile entre 2010 e Março de 2014) em um primeiro momento se traduziu unicamente na acção repressiva das forças policiais, dos chamados “carabineiros", sob o discurso de manutenção da ordem. 
Desde os anos 1980 que não se via mobilizações de rua tão grandes no país. Naquela época a sociedade chilena encarava a dura repressão do Estado policial de Pinochet, mas o Chile de 2011, vivendo agora numa democracia, é uma nação de profunda desigualdade social. Dos países da Organização para a Cooperação e Desenvolvimento Económico ou Económico $(O C D E)$ o Chile é o que tem piores índices de educação e maiores taxas de investimento privado. Quarenta e um anos depois da eleição de Salvador Allende, e trinta e oito anos depois da reacção autoritária do regime militar de Pinochet, a sociedade chilena testemunhou novamente a tensão entre movimentos sociais e Estado, na pressão por um sistema político com uma democracia de maior intensidade.

\section{Continuidades e rupturas}

"Se queremos que tudo continue como está, é preciso que tudo mude". A frase é de " O Leopardo", obra do escritor italiano Tomasi di Lampedusa, e expressa a tentativa de uma nobreza italiana de se manter no poder em face às grandes transformações do Risorgimento. Seu simbolismo já foi extensamente explorado em diversas análises políticas, no entanto, ela reganha o seu poder de expressão ao se estudar a transição democrática no Chile. Nela o poder transformador da mobilização popular deu lugar a uma negociação pacífica entre o regime militar e a oposição centro esquerda, pois ambos os lados eram temerosos da radicalização do lado oposto, o que gerou a base necessária para o consenso se estabelecer. A negociação garantia a manutenção de grande parte da herança institucional autoritária do regime militar e mantinha a autonomia do exército. Para a centro esquerda, assumir um papel de conciliação tinha como objectivo uma transição rápida e uma posterior tentativa de consolidação da democracia, removendo aos poucos a herança autoritária do regime militar. Apesar de conseguir negociar importantes reformas constitucionais, a Concertación foi incapaz de transformar mais radicalmente a institucionalidade da constituição de 1980 e reintroduzir os movimentos sociais na dinâmica política nacional. A dimensão crescente do movimento estudantil e a rapidez com que tem se tornado um importante ator político na sociedade chilena indica que a fim de compreender a dinâmica de sua formação social e as demandas políticas de seu discurso, torna-se necessário buscar o caminho histórico de sua identidade, sublinhando não só seu lugar de fala, mas, sobretudo, o vazio institucional que os trouxeram à luz. É importante ter em conta o período de transição democrática chilena pósditadura militar, definindo as rupturas e continuidades que tal transição proporcionou na recente democracia chilena. 
As manifestações dos estudantes chilenos ecoam um caminho de insatisfação com o grau de democracia alcançado, expresso tanto na carência de participação nas políticas públicas, quanto na adoção de uma modelo institucional neoliberal. As manifestações estudantis de 2011 não são isoladas, e não foram uma surpresa para os que acompanham a história recente do país. Já em 2006 com a "Revolução dos Pinguins", a bandeira da educação aparecia como um forte fator de mobilização popular com o intuito de questionar o consenso institucional da transição democrática, e sua continuidade em relação ao autoritarismo do governo de Pinochet. E mesmo em 2011 o país já sentia as evidências de uma crise eminente. Aconteceram greves e outras manifestações, como as do norte do país contra a alta do gás natural, as greves contra a construção da hidroéletrica em Aysén e a histórica reivindicação por direitos e terras da população Mapuche.

Nas palavras da então presidente da Federação dos Estudantes da Universidade do Chile (Fech), Camila Vallejo:

Quando entendemos que a demanda é muito mais do que o ensino gratuito de qualidade e para todos, mas permanece como um posição antihegemónica ao modelo de educação de mercado, percebemos que aqueles que sustentam este modelo dificilmente estariam disposto a ceder e a prescindir dos seus benefícios (Vallejo, 2012, p.127).

As reivindicações estudantis expressam um problema maior. A crítica dos estudantes de 2006 e 2011 desenvolve seu apelo mobilizador contra a dinâmica neoliberal inaugurada no governo de Pinochet. Por volta de vinte mil estudantes começaram marchando nas ruas em maio de 2011. Em julho e agosto já chegavam a cem mil, e seu auge aparece em fins de agosto numa manifestação no Parque O`Higgins com cerca de setecentos mil estudantes e a adesão de diversos outros sectores. A força dos estudantes se expressava na inquestionável demanda por uma educação totalmente pública, reivindicavam a educação como direito e não como mercadoria, ou seja, se mobilizavam para extinguir as actividades de lucro vinculadas a educação. Tal bandeira se fortaleceu na diversidade de acções colectivas, marchas, intervenções artísticas, assembleias, tomadas de universidades e liceus, que se espalharam pelas ruas de Santiago. O movimento estudantil havia conquistado de fato uma legitimidade política perante a sociedade, justamente porque seu discurso carregava uma transversalidade temática que agregou outras forças sociais. 
Para compreender a crítica a crescente institucionalização de um neoliberalismo económico presente no discurso dos estudantes, torna-se importante retornar ao marco histórico do pensamento neoliberal no continente, e a partir daí olhar para a ditadura chilena como a expressão máxima dessa corrente. O chamado Consenso de Washington de 1989, expressou a sintonia estratégica de um plano económico para a América Latina idealizado pelo FMI, o governo norte-americano e por alguns outros órgãos financeiros internacionais. Seu objectivo era promover uma aceleração na liberalização dos mercados latino-americanos, reduzir ao máximo a força do Estado e combater as políticas Keynesianas

A abordagem ideológica do neoliberalismo tentava se expandir em todos os sectores da sociedade, trabalhando a lógica do mercado e da competição em nome da busca de melhores serviços. Como afirma o historiador Italiano Loris Zanatta:

O objetivo básico era abrir as economias locais à concorrência internacional para obrigá-las a tornarem-se mais eficientes, e inovadoras, aumentando o papel do capital privado em detrimento do papel do Estado. Do comércio ao financiamento, do mercado de trabalho à segurança social, todos os setores foram transformados, ainda que em graus diferentes (Zanatta, 2012, p. 232).

O caso chileno é emblemático não só por ser o primeiro do continente, mas, sobretudo, por ter aliado tal dinâmica econômica a um governo autoritário. Com o passar do tempo, apesar da obtenção de um tímido crescimento económico inicial, os países de políticas neoliberais foram testemunhas de um aprofundamento das desigualdades sociais e económicas na sociedade. No caso chileno, a crise económica posterior acontece em conjunto a uma crise de legitimidade política que a transição democrática não iria resolver.

O historiador e economista húngaro Karl Polanyi, no início do século passado, afirmou que a separação absoluta entre economia e política (indivíduo e sociedade) é tarefa utópica. Apesar de não ter sido testemunha da ascensão neoliberal, muito do seu quadro teórico tem sido resgatado para se analisar o comportamento das novas dinâmicas liberais na economia. Os analistas que afirmam a actualidade de sua formulação teórica indicam que o desenvolvimento do capitalismo ainda obedece ao que Polanyi chamou de "duplo movimento"( Polanyi, 2012). Segundo esse conceito, a economia e as sociedades de mercado seriam regidas por princípios contraditórios constantes os quais definiriam a intensidade da ideia de livre mercado. O primeiro princípio seria o do próprio liberalismo económico, que sugere uma universalização de mercados auto-regulados, guiados pela ideia do laissez-faire e 
do comércio livre. A contrapartida estaria no princípio de uma auto-protecção social, que se articularia defensivamente dada certas condições materiais geradas pela sociedade de mercado. Logo, o "duplo movimento" historicamente delinearia um caminho dialético expressando suas distintas formas de atuação de acordo com sua época, suas demandas e seus atores sociais.

Nas palavras de Alejandro Foxley, ministro de habitação no governo do presidente Aylwin (o primeiro Presidente do Chile após a restauração da democracia em 1990): “O Chile é o país onde tem sido aplicado de forma mais rigorosa e consistente as políticas neoliberais e reformas. Sua experiência está prestes a testar o "caso puro". Este é verdadeiramente uma "experiência", quase laboratorial." (Foxley, 1988, p. 45)

O neoliberalismo não é só uma teoria económica, ele é sobretudo, uma teoria social, o seu desenvolvimento é parte do crescimento do capitalismo financeiro no mundo, redefinindo a estrutura de poder do próprio capitalismo. Sua doutrina expressa uma visão de mundo, possui uma carga cultural que compõe as dinâmicas subjetivas de sua esfera económica e social. Nesse sentido, uma doutrina do mercado acompanha uma financeirização das relações simbólicas que permeiam sua estrutura, a ideia de mercadoria se torna definidora de parâmetros sociais que antes não se enquadravam aos olhos do mercado.

\section{$O$ retorno às tradições}

Em dezembro de 2010, um jovem tunisiano pôs fogo ao próprio corpo em protesto por um sistema político mais democrático em seu país. Foi o ato fundador de uma série de revoltas em países árabes conhecida como Primavera árabe. Em 15 de maio de 2011, tinha início na Espanha uma grande mobilização popular a favor de uma democracia participativa e contra políticas de austeridade na União Europeia, os indignados, como ficou conhecido, iria se espalhar por outros países da Europa expressando uma insatisfação geral com o modelo de comunidade criada naquele continente. Em 17 de Setembro de 2011, na emblemática Wall Street em Nova York, centenas de americanos protestavam contra a desigualdade social e a influência das corporações financeiras nas decisões do país. Houve uma tendência por parte de alguns analistas em tentar construir uma organicidade nos quatro movimentos, por serem tão contemporâneos e por revitalizarem a rua como espaço de contestação política, seriam quase um levante em conjunto, anti-sistêmico mundial. Tal veredicto necessita de alguns cuidados, pois, apesar do fato de terem constituído a primeira grande onda de protestos 
mundiais em um mundo efectivamente globalizado - e com a determinante contribuição das redes sociais em sua organização - é necessário olhar para as particularidades históricas de cada movimento. Se a existência de alguma interacção entre eles é inegável, a tentativa de criar uma narrativa de insatisfação comum e global limita em muito a capacidade de compreensão de suas especificidades, da formação de seus atores políticos e da reivindicação de seus papéis sociais em cada país.

Os protestos de 2011 no Chile não inauguram nenhuma linguagem política nova de fato, sua importância está no resgate de uma tradicional força dos movimentos sociais naquele país, desde as mobilizações operárias e camponesas do início do século XX. Se a repressão da ditadura e as políticas neoliberais agiram no sentido de esvaziar a acção política desses movimentos, a transição democrática estabelece a possibilidade do retorno desse acção mobilizadora, mesmo com os fracos canais de abertura da Concertación para a sociedade civil. O golpe de 1973 pôs fim a um longo período de participação ativa dos movimentos sociais, pois o governo da Unidade Popular se caracterizou por incentivar o diálogo com os movimentos sociais, e o Estado se tornou aberto a tais iniciativas colectivas. No entanto, o golpe militar de Pinochet em 1973 tentou extinguir esse modelo institucional, para isso a constituição de 1980 foi determinante, a partir dela se criou um novo regime político esvaziando o Estado de suas prerrogativas participativas. A transição para a democracia feita pelo governo de coalizão não se propôs a transformar o modelo institucional da ditadura, manteve em grande medida a distância entre Estado e sociedade. Portanto, pode-se afirmar que o movimento estudantil de 2011 obteve sucesso exactamente por conseguir captar esse anseio por uma efectiva democratização da sociedade chilena, a bandeira da educação representava nada mais que a própria falta de legitimidade do regime político sacramentado ainda pela constituição de 1980.

A continuidade do modelo institucional autoritário após o plebiscito de 1988 não foi resultado de uma escolha por parte do governo da Concertación, mas expressou um grande temor pela reacção opositora a possíveis medidas mais radicais de transformação social. $\mathrm{O}$ processo de democratização teria de ser gradual e negociado, a necessidade do consenso revelou a existência de um grande trauma naquela sociedade. O governo de Allende havia incentivado a efervescência dos movimentos sociais, abriu um canal de diálogo com eles, apresentando um modelo de democracia de maior intensidade. No entanto, se o regime de Allende significou para a esquerda a excitante possibilidade de se viver um socialismo democrático, a reacção a esse projeto foi extremamente violenta. Durante a ditadura a 
sociedade chilena testemunhou o horror de uma intensa repressão institucionalizada no Estado de Pinochet. A radicalidade desse movimento de ruptura com o socialismo de Allende podou a esquerda de seu ímpeto utópico e de sua mobilização de base.

\section{A transição}

O historiador Steve J. Stern afirma que um dos maiores legados do regime de Pinochet foi o que chamou de "politicidio", uma sistemática desmobilização política da sociedade chilena, que teria repercussões nos primeiros anos de governo da Concertación. Anos de neoliberalismo, de fragmentação e atomização social afectaram a capacidade de mobilização social da sociedade chilena, e a democracia negociada por meio de alianças com sectores conservadores evidenciou que o Estado chileno continuaria blindado para as acções colectivas dos movimentos sociais. Apesar disso, é possível afirmar que o sentimento por transformações sociais mais intensas, embora reprimido, continuou a construir redes sociais de atuação em menor escala. Se tal sentimento havia sido capitalizado pelo Estado durante o governo da Unidade Popular, após o governo militar se tornou ausente da esfera estatal, sobrevivendo nos movimentos sociais. É através dele que irão se formar importantes movimentos por direitos humanos, pela causa dos Mapuches (povo indígena da região centrosul do Chile) e a dos estudantes no século XXI.

Segundo o sociólogo chileno Manuel Antonio Garretón, o projeto de Pinochet de, através da institucionalização na constituição de 1980, realizar a passagem de um regime militar a outro de carácter autoritário em 1989, não foi completamente desmantelado, mesmo não ganhando o plebiscito em 1988. Os sectores que apoiavam o governo de Pinochet conseguiram manter a autonomia corporativa do exército na política e criaram uma barreira constitucional que permitia que, mesmo com a Concertación obtendo uma maioria na câmara e no senado, tinha as condições de vetar os projectos das reformas constitucionais e das leis orgânicas. O presidente eleito não tinha o poder de mudar o chefe das forças armadas e os militares ainda detinham o direito de nomear nove senadores, cerca de 1/5 da composição do senado, com um sistema eleitoral desproporcional binominal a direita ainda conseguia número de votos suficientes para vetar as reformas.

A expressão de continuidade política se evidenciava em vários aspectos, um dos mais notórios era a manutenção de Pinochet como chefe das forças armadas. Apesar do crescimento económico inicial e uma aparente sensação de estabilidade e tranquilidade, o 
primeiro governo da transição enfrentava o resultado de anos de políticas neoliberais, altos índices de pobreza e grande desigualdade social. A estratégia de evitar conflitos políticos, consolidar a democracia para então expandi-la a sectores marginalizados e ampliar as políticas de modernização encontrou um limite, a herança institucional autoritária. A Concertación manteve a dinâmica de negociações com a direita, de um lado o partido da "Renovacion Nacional", os quais queriam apenas exercer uma oposição na nova democracia, de outro havia a UDI (Unión Demócrata Independiente), partido saudoso do regime militar. O esgotamento do modelo da Concertación aos poucos foi reascendendo as demandas populares e fazendo com que movimentos se organizassem para pressionar o governo a romper com as instituições remanescentes do regime militar.

\section{A nova geração supera o trauma}

As políticas de educação que são escolhidas por um governo são sempre emblemáticas da visão ideológica que o projeto político deste governo carrega, e expressam uma parte importante do caminho institucional que um governo pretende traçar. No caso chileno, a derrota de Pinochet no plebiscito de 1988 impulsionou a elite política do regime militar a tentar institucionalizar o máximo de entraves autoritários ao desenvolvimento de alguma soberania popular mais radical. Nesse sentido, uma democracia só seria aceita pela direita se a estrutura do seu poder se mantivesse, e a única maneira de tal condição se efectivar era através da consolidação das instituições neoliberais. A diminuição da força do Estado e a despolitização da sociedade civil garantiria os interesses dessa elite, e a negociação com os partidos da Concertación aconteceu no intuito de garantir essa mesma estrutura autoritária; ela seria responsável por assegurar o bloqueio de tentativas de se democratizar o Estado.

A pesquisadora da educação Maria Angélica Oliva defende que a desigualdade educativa no Chile se aprofundou durante o período do regime militar, basicamente devido a três factores. O primeiro diz respeito a uma chave de análise da educação pública chilena na sua relação com o Estado. Maria Angélica apresenta a dicotomia entre "Estado docente" e "Liberdade de ensino" e afirma que através de um caminho dialético, os dois pólos permearam toda discussão histórica a respeito da educação pública no Chile. O segundo evidencia a construção de um Estado subsidiário e a ruptura da educação enquanto bem público e direito básico. O terceiro fator que justifica o crescimento da desigualdade educativa é a institucionalização neoliberal na constituição de 1980, ela aplica os preceitos ideológicos 
neoliberais para todas as esferas da sociedade, reconfigura a noção de direitos, e a partir de uma ótica utilitarista e mercantilizadora relega ao mercado a função de regular o acesso a educação.

A estrutura do sistema de educação chileno contem três níveis, no primeiro estão as escolas privadas, tradicionalmente ligadas ao ensino católico. Pagas e com bons resultados, geralmente atendem a classe mais alta do país. No segundo encontra-se as semi-privadas, essas possuem financiamento do Estado mas são geridas por empresas privadas chamadas de "sostenedores", podem ser gratuitas ou pagas com um tipo de financiamento compartilhado com as famílias. No terceiro, a educação estritamente gratuita, municipalizada, na grande parte destinada às classes mais pobres, desde a constituição de 1980 não há ensino público federal, a educação foi descentralizada, e o Estado assumiu uma dinâmica unicamente subsidiaria. Em relação a educação superior no Chile, tanto pública quanto privada, são pagas. A transformação no modelo de financiamento das universidades públicas e a adesão da liberdade de mercado colaborou para o grande crescimento do número de universidades privadas. Diferente das privadas, as universidades públicas não exigiam uma pontuação mínima para o ingresso, bastava ser apto para o pagamento que o aluno era aceito. Para as classes mais pobres só restava a opção de pedir algum tipo de financiamento para poder pagar as mensalidades, assim as universidades ligadas a grandes empresários e aos bancos obtiveram a possibilidade de lucrar com as dívidas familiares. As classes mais pobres acabaram excluídas e não tiveram acesso ao ensino superior. A elaboração teórica de tal nova abordagem frente a educação se fundamentou na valorização da liberdade de ensino, a responsabilidade sobre a educação transferir-se-ia do Estado para a família, revelando assim todo o contexto neoliberal de atomização social contida na carta constitucional.

\section{Movimento Estudantil}

Historicamente, o movimento estudantil sempre constituiu uma força social importante no cenário político chileno, seu discurso transcendia as demandas educativas e terminava por ecoar as reivindicações por mais democracia e justiça social de toda a sociedade. Os movimentos de 2006 e 2011 expressam demandas que são irreconciliáveis com a visão ideológica das instituições governamentais, e não se pode atendê-las sem refletir sobre a transformação do modelo político e institucional. Tal característica apresenta um quadro de conflito político que a democracia atual sempre procurou evitar. As diferenças ideológicas 
não mais podem ser colocadas à sombra, e a política pelo diálogo sem a incorporação de movimentos sociais apresenta sinais claros de esgotamento. Sua legitimidade rui ao som dos cânticos de protestos das ruas de Santiago, e novamente a rua se torna uma forte arena política. A nova geração de estudantes supera o trauma da violência dos militares e resgatam o sentimento de transformação.

Durante os duros anos do governo de Pinochet a ideia de "liberdade de ensino" ganhou força dando eco às doutrinas neoliberais assumidas como principais diretrizes econômicas. Em 7 de março de 1990, em um dos seus últimos atos como presidente, o general promulgou a LOCE (Ley Organica Constitucional de Enseñanza),que no seu artigo terceiro indica que o Estado tem a responsabilidade de garantir, especialmente, o direito à liberdade de ensino. A reforma promovida pela LOCE transforma todo o cenário educativo, desde o sistema de financiamento até o sistema de contratos e dependência dos professores. Estes deixam de ser funcionários públicos e são inseridos na dinâmica do mercado, apresentando uma nova realidade de precarização dos contratos de trabalho. Os subsídios estatais são dados aos alunos ou de acordo com a demanda. Se institui quatro tipos de estabelecimentos educativos: municipais, colégios privados subvencionados, particulares pagos, e corporações educacionais dependentes de organizações empresariais.

Mesmo após o governo de centro-esquerda da Concertación, as reformas realizadas não foram suficientes para transformar radicalmente a diretriz neoliberal no ordenamento jurídico, dessa forma o modelo de Estado subsidiário permanece como paradigma principal. Portanto, a desigualdade educativa continuou sendo um empecilho para o desenvolvimento democrático do país, e a quantidade de bolsas que o Estado concedia era proporcionalmente menor que a de créditos (a lógica do endividamento familiar prevalecia). Mesmo após os governos da Concertación, dos democratas cristãos Aylwin e Eduardo Frei até o primeiro governo socialista de Michelle Bachelet (de 2006 a 2010), o Estado não foi capaz de combater de maneira eficaz a desigualdade gerada. Com a eleição de Sebastian Piñera, a ascensão do partido de direita Renovación Nacional reverbera um novo momento na política chilena pós ditadura, o retorno da direita ao poder evidenciou o fracasso da coligação de centro-esquerda em expandir as instituições democráticas e desconstruir o modelo neoliberal.

O movimento estudantil se fortaleceu ao longo das décadas de 1990 e 2000. O mochilazo no início do século XXI já apresentava a indignação dos estudantes do ensino secundário, principalmente no que se referia ao debate sobre o passe escolar. Desde esse 
primeiro momento podia-se notar um novo modelo de organização, horizontal, colectivo, cujas decisões aconteciam por meio de assembleias. As demandas do movimento foram constantemente ignoradas pelos sucessivos ministros da educação, até que em 2006, durante o primeiro governo socialista de Bachelet, estudantes voltaram às ruas naquela que ficou conhecida como a "Revolução dos Pinguins". Novamente alunos do ensino secundário se mobilizaram exigindo a gratuidade do exame de seleção para a universidade (PSU) e do passe escolar, melhor qualidade da merenda escolar e melhores instalações sanitárias nos colégios. Por fim, em 2011 os universitários que foram para as ruas conseguiram reunir diversas outras camadas sociais com a mesma demanda educativa, mas agora com uma agenda por participação e transformação do sistema político chileno. A primeira marcha foi convocada no dia 12 de maio pela Confederação dos Estudantes do Chile (CONFECH). A partir desse dia o movimento começou a crescer, outras federações de estudantes aderiram, as marchas se tornaram mais frequentes, ao mesmo tempo em que escolas e universidades eram ocupadas pelo país. Até que no dia 16 de junho a $\mathrm{CONFECH}$, os estudantes secundários e o colégio de professores realizaram uma parada total, reunindo cerca de oitenta mil pessoas na Alameda em Santiago, na capital chilena. Algumas lideranças ascenderam para tomar a frente das marchas, entre elas estava a jovem Camila Vallejo, nas suas palavras: “...o movimento estudantil conseguiu ressurgir na década dos anos noventa, reivindicando as liberdades perdidas, questionando o modelo de gestão autoritário e chamando para a participação. Se mobilizaram novamente pela democratização, como alternativa à investida privatizadora que estavam impondo.” (Vallejo, 2012, p. 79)

Os quatro pontos reivindicados pelos estudantes são: a estatização do modelo educacional, a gratuidade, a melhor qualidade de ensino e a proibição de qualquer lucratividade. Conforme o movimento crescia outras forças sociais incorporavam suas próprias demandas, aos apelos dos estudantes se juntaram gritos por uma nova constituição, pela nacionalização da indústria do cobre e por uma reforma tributária. O presidente Piñera respondeu à crescente organização dos estudantes com algumas iniciativas, como a GANE (Gran Acuerdo Nacional por la Educación), que, embora apresentasse algumas intenções de mudança, não estabelecia prazos e não contemplava nenhuma transformação mais radical na estrutura do sistema. O governo de Piñera negociou directamente com o movimento e tentou sem sucesso fazer com que o movimento se contentasse com a ida de algumas de suas demandas para o Congresso. O discurso adotado pelo governo de Piñera intensificou o processo de crise de credibilidade e de legitimidade que o sistema político chileno vivia desde 
os governos da Concertación. Já no início de 2011, na cidade de Punto Arenas, foi organizado um grande protesto contra o aumento do preço de gás acima do que estipulado na campanha presidencial; em março a ministra de habitação de Piñera renunciou após uma denúncia de uso de fundos públicos em favor de empresas privadas; e em maio, um pouco antes dos protestos estudantis, aprovava-se o projeto da hidroeléctrica Hidroaysen, reprovado por grande parte da sociedade civil pelos possíveis danos causados ao meio ambiente. Desde a ditadura o sistema político inaugurado pelos militares, e que teve um grande grau de continuidade no governo da Concertacion, vinha evidenciando sua falta de legitimidade democrática pela falta de capacidade em suprir as demandas populares que surgiam. A tão almejada governabilidade havia sido alcançada, no entanto, a crescente mobilização dos movimentos sociais, dos Mapuches aos estudantes, fez transparecer os duros limites da democracia chilena.

\section{Movimento que segue}

Desde 2011, os estudantes chilenos têm conseguido dos governos algumas reformas importantes. Contudo ainda são superficiais, e não transformaram de fato o sistema de educação do país como exigido pelo movimento. A querela é complexa, para se mudar a o sistema de educação conforme indicado pelos estudantes é preciso redefinir a relação do Estado para com a sociedade, mexer nas bases ideológicas desse Estado, alterar todo seu modelo constitucional. Para a ideia do Estado docente retornar e esse Estado retomar total controle sobre a educação, torna-se necessário a nacionalização das maiores riquezas do país para que seja viável financeiramente tal empreitada. Apesar dessas dificuldades estruturais, os estudantes chilenos já conseguiram obter um feito histórico, sua persistente mobilização contagiou outros sectores sociais que alinharam às suas demandas, conseguiram trazer à luz as contradições do modelo democrático e sua falta de legitimidade política. Nesse sentido, a negociação direta com o poder executivo gerou um ganho extraordinário de força aos estudantes e apresentou ao país que a sociedade civil está se organizando coletivamente e vai buscar ampliação da democracia no país.

O movimento não diminui, e mostrou uma força constante na manutenção do discurso de 2011. Bachelet retornou ao palácio La Moneda em 2014 defendendo uma reforma educativa contundente, baseada na educação pública e gratuita, e obteve apoio de grande parte da liderança do movimento estudantil. A ideia que a educação será de qualidade, gratuita e 
sem lucro nem segregação, foi uma das grandes bandeiras eleitorais da nova presidente socialista. No entanto, na prática o que se tem visto é um governo tentando ainda agradar os diversos sectores, tanto estudantes quanto reitores de universidade privadas. As reformas apresentadas ainda são consideradas moderadas por grande parte da população. Em janeiro de 2015 novas medidas políticas saíram do papel, entre elas a redefinição de um órgão federal de regulação da educação superior - o Conselho Nacional de Educação - e a proibição de selecção de alunos por parte de estabelecimentos que recebem dinheiro público . Apesar do pacote de reformas da presidente socialista abarcar enfim a proibição de lucros em qualquer estabelecimento de ensino, ele ainda mantém a possibilidade de instituições educacionais serem arrendadas por empresas privadas. Em maio deste mesmo ano as manifestações continuaram e os confrontos com a polícia se intensificaram ocasionando a morte de dois estudantes após uma grande manifestação na cidade de Valparaiso.

Alguns líderes estudantis se tornaram deputados nas eleições de 2013, como é o caso da activista comunista Camila Vallejo, da então $2^{\circ}$ secretária da juventude comunista Karol Cariolas e do presidente da Federação dos Estudantes da Universidade Católica (Feuc) Giorgio Jackson. A atuação parlamentar deles tem conseguido a aprovação de leis mais rígidas contra o lucro nos estabelecimentos de ensino. Mesmo realizando um trabalho em prol da educação, têm recebido algumas críticas pela opção de se incorporarem à institucionalidade, cuja legitimidade questionavam. Apesar de grande parte da liderança de 2011 terem sido eleitos representantes no Congresso, o movimento estudantil mantém sua força de mobilização, novas lideranças surgem na tentativa de unificar as demandas da crise do sistema em um só discurso. O colectivo de esquerda Nueva Mayoria que trouxe de volta Bachelet ao governo, vai enfrentar nesse novo mandato presidencial (até 2018) um movimento estudantil que lutará por sua autonomia de mobilização. A nova presidente da Fech desde fins de 2013, Melissa Sepúlveda, que se autodefine como libertária e anarquista, tem se tornado a nova cara da mobilização estudantil chilena. Como membro do colectivo feminista La Alzada, o discurso de Melissa traz o apelo pelo aumento da transversalidade do movimento, na tentativa de incorporar mobilizações por outras demandas políticas e assim criar um grande movimento social.

\section{Em busca de uma transformação radical?}


A sociedade chilena vive um importante momento de transformações sociais, o actual questionamento do modelo político pelos estudantes coloca em evidência a continuidade histórica de alguns conflitos presentes na história recente do país. O golpe militar de 1973 representou a violenta reacção a um governo que promovia a abertura do Estado para os movimentos sociais, que tentava desenvolver um inédito projeto democrático de socialismo no país. Tal reacção conseguiu de fato estabelecer um novo modelo institucional onde o Estado seria minimizado em todos as esferas da sociedade, e esta viveria um período de intensa despolitização e fragmentação dos movimentos sociais. O regime autoritário de Pinochet foi capaz de redefinir ideologicamente o ordenamento jurídico do sistema político, e foi através do mesmo que sofreu sua grande derrota. A oposição centro-esquerda ao regime militar dirigiu um período de transição democrática negociada, abdicando do conflito em nome de uma futura consolidação do Estado democrático, no entanto, para tal foi preciso aceitar a continuidade institucional de um sistema político autoritário, limitando os ganhos democráticos reais.

A mobilização estudantil de 2011 evidenciou três aspectos importantes dessa sociedade chilena para o mundo, o primeiro aponta para o esgotamento do consenso político acerca do governo da Concertación. O segundo indica a superação do trauma do retorno autoritário e seu aparato repressivo por parte de uma nova geração de jovens, que ao dialogarem directamente com o histórico de mobilizações populares conseguem resgatar a nostalgia de uma velha geração que participou ativamente dos movimentos sociais durante o governo da Unidade Popular na década de 1970. O terceiro ponto incide sobre a herança institucional do regime militar na democracia chilena de hoje. Os estudantes se reúnem e gritam não só pela educação pública de qualidade, mas também, e sobretudo, contra o modelo neoliberal institucionalizado pela constituição de 1980 que se constituiu a base jurídica do regime militar. O neoliberalismo é indicado como responsável pela intensificação da desigualdade social chilena, que apesar da estabilidade política e económica conseguida pelos primeiros governos da Concertación, manteve os limites da regulação estatal frente a mercantilização das relações entre sociedade e Estado.

O movimento estudantil de 2011 expressou mais do que uma simples organização colectiva por demandas educativas. Ele se expandiu a partir de um discurso anti-sistémico e o seu grande alcance evidenciou a crise de legitimidade que o Estado vivenciava. Apesar de seu carácter altamente político, o movimento não foi cooptado por nenhum partido político, mesmo tendo alguns de seus líderes se filiado ao Partido Comunista. Nesse sentido o seu 
apelo anti-sistémico se torna o seu principal combustível e é o que permite que estabeleça o diálogo da experiência chilena com outras pelo mundo. O ponto de conexão é o próprio retorno às ruas, a organização colectiva em nome de uma transformação radical, e a renovação da utopia de uma sociedade mais justa e democrática. Assim como no Chile, os movimentos sociais pelo mundo seguem questionando o modelo de seus Estados, e indagam a legitimidade de seus sistemas políticos e evidenciando a tensão entre movimentos sociais e a política estatal. A ânsia por participação é a ferramenta de seu apelo utópico, e é o que contagia pessoas de classes e ideais distintos. Os estudantes foram os grandes protagonistas do retorno dos movimentos sociais; uma nova geração que ignorou o trauma de uma possível reacção autoritária, mostrou que o Estado não tinha mais a exclusividade do espaço político e que era incapaz de suprir os anseios de transformações sociais mais radicais.

Em 2008 foi realizado a Conferencia Regional de Educação Superior na América Latina e Caribe, na Colômbia, sua declaração final foi:

\begin{abstract}
O ensino superior é um direito humano e um bem público social. Os Estados têm a obrigação primordial de garantir este direito. Os estados, as sociedades nacionais e as comunidades académicas devem ser os únicos a definir os princípios básicos sobre os quais a educação dos cidadãos se baseia, garantindo que ela é relevante e de qualidade. A natureza de bem público social do ensino superior é tanto maior quanto o acesso a ele é um direito real de todos os cidadãos. As políticas nacionais de educação são necessárias para promover o acesso ao ensino superior de qualidade por meio de estratégias e ações consequentes ${ }^{1}$.
\end{abstract}

Os protestos no Chile são também resultado da expansão do discurso dos direitos humanos no mundo nas últimas três décadas, a cada vez mais forte atuação de instituições internacionais de protecção e promoção desses direitos em conjunto com o trabalho de investigação das ONGs ajudou a estabelecer um consenso a respeito desses direitos fundamentais. Faz parte do mundo globalizado um certo constrangimento por não se alinhar às dinâmicas de tais direitos, mesmo com alguns possíveis questionamentos em relação a eficácia dessas dinâmicas. Recuperando a ideia de "duplo-movimento" de Polanyi, a organização dos estudantes chilenos são parte de um movimento de protecção social, de reganho do espaço público e político por parte da sociedade civil, na contrapartida da guinada neoliberal realizada pelo regime militar. Para o futuro a coesão de classes no discurso anti

${ }^{1}$ Disponível em: http://www.oei.es/salactsi/cres.htm . Acesso em : 7 de julho de 2014. 
sistémico pode apresentar sinais de desgaste ou mesmo fazer transparecer as distinções de ideais dentro de um mesmo movimento heterogéneo. A briga por participação abre espaço para se pensar a direcção que o país quer tomar efectivamente, e em como garantir a solidez e a permanência de instituições mais democráticas tendo que dialogar com forças de interesses muitas vezes contraditórias. Esse é o desafio do movimento estudantil para os próximos invernos.

\section{Referências bibliográficas}

ATRIA, Fernando. La Mala Educación. Santiago: Catalonia, 2012.

FOXLEY, Alejandro. Experimentos neoliberales en América Latina. México: Fondo de Cultura Económica, 1988.

GARCÉS, Mario. EI Despertar de la Sociedad: Los movimentos sociales en América Latina y Chile. Santiago: LOM Ediciones, 2011.

GARRETÓN, Manuel A. La Redemocratización politica en Chile: transición, inauguración y evolución. Santiago: Estudos Publicos, nº42, pp. 102-133,1991.

HARVEY, David. Neoliberalismo: História e Implicações. São Paulo: Edições Loyola, 2008.

OLIVA, Maria A. "Politica Educativa y Profundizacion de la desigualdad en Chile: Educational Policy and deepening of unequality in Chile". Santiago: Estudios Pedagógicos XXXIV, Nº 2: 207-226, 2008.

POLANYI, Karl. A Grande Transformação: As origens políticas e económicas do nosso tempo. Lisboa: Edições 70, 2012.

ROBERTS, Kenneth M. Deepening Democracy? The Modern Left and Social Movements in Chile and Peru.California: Stanford University Press, 1998.

SALAZAR, Gabriel. En el Nombre del Poder Popular Constituyente. Santiago: LOM Ediciones, 2011.

STERN, Steve J. Reckoning with Pinochet: The Memory Question in Democratic Chile, 1989- 2006. Durham: Duke University Press, 2010.

VAllejo, Camila. Podemos cambiar el mundo. Cidade do México: OceanSur, 2012.

VARGAS, Viviane B. Neoliberalismo, protesta popular y transición en Chile, 1973 -1989. Política y Cultura, Cidade do México, núm. 37, pp. 85-112, primavera 2012.

ZANATTA, Loris. Historia de America Latina. Buenos Aires: Siglo Veintiuno, 2014. 
ARTIGO ENVIADO EM: $10 / 08 / 2015$ ACEITO PARA PUBLICAÇÃO EM: 28/03/2016 